Nuevos bilingüismos y viejas categorías en la formación inicial de docentes

\author{
New bilingualisms and old categories \\ in initial teacher education \\ Virginia Zavala \\ Pontificia Universidad Católica del Perú \\ vzavala@pucp.edu.pe \\ Roberto Brañez \\ $\overline{\text { Universidad Antonio Ruiz de Montoya }}$ \\ roberto.branez@uarm.pe
}

Recibido: 08-08-2017

Aprobado: 01-10-2017 


\title{
Resumen
}

Sobre la base de una perspectiva del bilingüismo como práctica social y de recientes cuestionamientos de la lingüística aplicada a categorías vinculadas con el aprendizaje de lenguas, analizamos las limitaciones de la división entre primera lengua y segunda lengua ( 11 y L2) para abordar la complejidad de bilingüismos en un programa de formación docente en educación intercultural bilingüe (EIB) en una universidad de la capital peruana. Luego de un breve marco teórico y de un análisis documental sobre cómo las políticas lingüísticas y educativas conceptualizan al sujeto bilingüe y al destinatario de la EIB, presentamos dos secciones de análisis. En la primera, abordamos los desencuentros entre la manera en que la institución de educación superior representa a los estudiantes de formación docente en EIB en relación con las lenguas que manejan y la forma como estos viven sus diferentes bilingüismos. En la segunda, mostramos tres narrativas de estudiantes relacionadas con sus trayectorias de bilingüismo a lo largo de sus vidas. En estas dos secciones, encontramos grandes diferencias entre la experiencia de los sujetos reseñados y las categorías lingüísticas e identitarias que se les impone desde el discurso institucional, y vemos cómo categorías como L1 versus L2 ya no resultan tan útiles en una realidad cambiante que se caracteriza por los flujos y movimientos culturales a través de comunidades y contextos.

Palabras clave: Educación intercultural bilingüe, trayectorias de bilingüismo, lingüística aplicada, primera y segunda lengua, práctica social

\begin{abstract}
Based on a perspective of bilingualism as social practice and recent questioning of certain concepts attached to language learning from the field of applied linguistics, we analize the limitations posed by the distinction between first and second language (L1/L2) for addressing the complexity of bilingualisms in a teacher training program focused on intercultural bilingual education (IBE) at a university in Lima (Peru's capital city). After a brief theoretical framework and a discussion of how linguistic and educational policies conceptualize the bilingual subject and the target of IBE, we present our analysis organized into two sections. In the first one, we address the contradictions between the way the institution represents the students in relation to their languages and the way they live their diverse bilingualisms. In the second section, we display three narratives from students in relation to their bilingual trajectories along their lives. In these two sections, we find important differences between the students' experience and the identity and linguistic categories that the institutional discourse imposes on them; and we verify that categories such as L1 and $L 2$ are no longer that useful in a changing reality characterized by cultural mobility and fluxes through communities and contexts.
\end{abstract}

Keywords: Intercultural bilingual education, bilingual trajectories, applied 62 I linguistics, first and second language, social practice 


\section{Nuevos bilingüismos y viejas categorías en la formación inicial de docentes}

\section{Introducción}

El escenario sociolingüístico en el Perú ha ido cambiando en las últimas décadas, debido -entre otros aspectos- a procesos de globalización y avances tecnológicos, así como a aspectos de movilidad social y migración. Este nuevo escenario desafía divisiones que se han desarrollado en torno a la educación intercultural bilingüe (EIB) desde hace más de cuatro décadas, tales como la de tradición versus modernidad, lo local versus lo global, lo rural versus lo urbano, lo indígena versus lo no indígena, etc. En este artículo, queremos mostrar que la división entre primera y segunda lengua (o L1 y L2), usada desde los inicios de la EIB en el país, ya no se sostiene en muchos contextos y puede incluso terminar sobre-simplificando la compleja realidad de las trayectorias de los bilingües de hoy.

En el mundo académico, ha habido un vuelco desde una perspectiva modernista y positivista del lenguaje hacia una perspectiva crítica y posestructuralista (García et al., 2017). Esto ha generado que en la lingüística aplicada se hayan empezado a cuestionar muchas de las asunciones que se dieron por sentadas durante décadas (Pennycook, 2010). Por ejemplo, desde una perspectiva del bilingüismo como práctica social, se problematizan nociones cerradas, unitarias y reificadas de «lengua», «cultura» e «identidad», y conceptos como los de «hablante nativo», «diglosia», «lengua materna» $\mathrm{y}$ "comunidad de habla» (Blommaert, 2010; Pennycook, 2010; Heller, 2011), que -cada vez más- son difíciles de operacionalizar en la investigación empírica. Así también, la división entre L1 y L2 ha sido criticada por algunos autores (García, 2009; Canagarajah, 2013), pues el aprendizaje de lenguas ocurre a lo largo de toda la vida de un modo recursivo. En todo caso, debemos tener claro que no estamos ante realidades que son independientes de sus representaciones, sino, más bien, ante constructos sociales creados en el marco de una disciplina. Cuando estos constructos ya no resultan útiles para comprender la realidad, debemos hacer un alto en el camino y repensar nuestras categorías teóricas (Pennycook, 2001).

En este artículo, compartiremos casos de bilingües que no calzan con la representación del discurso oficial y que necesitan ser urgentemente atendidos por la política educativa peruana. Los datos que aquí presentamos provienen de un trabajo de campo en una universidad de la capital que está impartiendo formación docente en EIB en el marco de un programa de becas provisto por el Estado peruano desde hace varios años ${ }^{1}$. Luego de un breve marco teórico

1. Nos referimos al programa Beca 18 , uno de los programas de inclusión social del Gobierno y del Ministerio de Educación del Perú, que tiene como objetivo la equidad en el acceso a la educación superior de los jóvenes en situación de pobreza y pobreza extrema. 
sobre el bilingüismo como práctica social, presentaremos dos secciones de análisis. En la primera, abordaremos los desencuentros entre la manera en que la institución de educación superior representa a los becarios EIB en relación con las lenguas que manejan y la forma como estos viven sus diferentes bilingüismos. En la segunda, mostraremos tres narrativas de estudiantes relacionadas con sus trayectorias de bilingüismo y multilingüismo. En estas dos secciones, encontraremos grandes diferencias entre la experiencia de los sujetos reseñados, y las categorías lingüísticas e identitarias que se les impone desde el discurso oficial. Asimismo, veremos cómo categorías como L1 versus L2 ya no resultan tan útiles en una realidad cambiante que se caracteriza por los flujos y movimientos culturales a través de comunidades y contextos.

\section{El discurso oficial}

En varios documentos oficiales de política educativa del Perú, se hace alusión a la diversidad como un factor fundamental para el desarrollo del país y a la EIB como una modalidad que debe implementarse en todas las etapas, niveles y modalidades del sistema educativo peruano. Sin embargo, en otros documentos -y en otras circunstancias de interacción social-, se tiende a contradecir lo anterior, y a conceptualizar al sujeto bilingüe y al destinatario de la EIB desde una perspectiva bastante reduccionista. De hecho, lo que parece ocurrir es un fenómeno de «borrado» de una variedad de sujetos bilingües desde la política educativa oficial. Con «borrado», estamos haciendo referencia a un proceso mediante el cual se invisibiliza la información que resulta inconsistente con una representación ideológica particular (Irvine \& Gal, 2000). En el Perú, el bilingüe (nos vamos a referir desde ahora al bilingüe quechua-castellano) parece ser solo aquel que aprendió primero la lengua originaria como «lengua materna», que proviene de una zona rural, que no «mezcla» las lenguas, y que -además-encarna la cosmovisión andina y un tipo de identidad «ancestral». El beneficiario de la EIB sería precisamente solo este tipo de sujeto.

Aunque en la última versión de la Política Sectorial de la Educación Intercultural y la Educación Intercultural Bilingüe del año 2016 (Ministerio de Educación [Minedu], 2016), y de la Política Nacional de Lenguas Originarias, Tradición Oral e Interculturalidad del año 2017 (Ministerio de Cultura [Mincu], 2017), se pueden visualizar discursos alternativos a los asentados históricamente, un análisis de las diferentes políticas del sector educativo (y de otros sectores también) revela lo mencionado en el párrafo anterior. En el artículo 20 de la Ley General de Educación, Ley 28044 (2003), se estipula que la Educación Bilingüe Intercultural garantiza el aprendizaje en la lengua materna de la población estudiantil y del castellano como segunda lengua, así como el posterior aprendizaje de lenguas extranjeras. En la Ley 29735 (2016), que regula el uso, preservación, desarrollo, recuperación, fomento y difusión de las lenguas originarias del Perú, se señala que toda persona tiene derecho a recibir una 64 I educación en su lengua materna y en su propia cultura bajo un enfoque de 
interculturalidad. La misma Política Nacional de Lenguas Originarias, Tradición Oral e Interculturalidad mencionada líneas arriba no fue ajena a estas representaciones en versiones anteriores al documento final. Recordamos, por ejemplo, que, al referirse a la Política Nacional de EIB, solo mencionaba el derecho de los niños a recibir una educación en su lengua materna: «Toda persona tiene el derecho a una educación de acuerdo con su cultura y en su lengua materna, ya sea esta una lengua indígena o el castellano». A pesar de que este punto fue modificado en la versión final, es difícil combatir la representación del destinatario de la EIB desde una perspectiva reduccionista. Así, por ejemplo, cuando se menciona la forma de atención de Revitalización Cultural y Lingüística que se viene implementando en instituciones educativas EIB de educación secundaria, se plantea que esto "permite que los estudiantes puedan completar la educación básica en su lengua materna» (Mincu, 2017). Sabemos, sin embargo, que en las secundarias (incluso de zona rural) hay muchos estudiantes que no tienen a la lengua originaria como lengua materna, y que igual deberían tener el derecho de recuperarla y desarrollarla. Ahora bien, a nivel de las regiones, también se reproduce este discurso (Zavala Mujica, Córdova \& Ardito, 2014), aunque no daremos detalles sobre este punto por obvias razones de espacio. En todo caso, es importante darnos cuenta de que, a pesar de los cambios que se comienzan a avizorar en los últimos años, la representación de los sujetos de derecho solo como aquellos que tienen a la lengua originaria como «lengua materna» está muy asentada en el sentido común.

Las políticas lingüísticas ejercen poder con el objetivo de fijar límites discursivos sobre lo que se considera normal o factible en términos educativos (Johnson, 2013). De esta manera, la EIB reifica la noción de lengua materna y restringe la posibilidad de que una mayor cantidad de estudiantes sean sujetos de derecho a una educación intercultural bilingüe en el Perú. Esta representación -tan asentada históricamente- no necesariamente corresponde con las experiencias de vida de las comunidades de lenguas minorizadas en el Perú $y$ en el mundo, y borra a los hablantes del quechua como lengua de herencia (Van Deusen-Scholl, 2003), a los bilingües emergentes (García, 2009) o a los nuevos hablantes de lenguas indígenas (Jaffe, 2015). Más aún, esta persistente dicotomía entre hablantes de quechua y hablantes de castellano como lengua materna, en la que solo los primeros tendrían derecho a recibir una EIB y que no contempla una diversidad de hablantes bilingües que no satisfacen esas características, encaja en una estricta división entre lo urbano y lo rural, que sitúa a los beneficiarios de la EIB solo en la zona rural y que invisibiliza a los bilingües de la zona urbana.

\section{El bilingüismo como práctica social}

Recientemente, se ha empezado a criticar una noción de bilingüismo desde una perspectiva monolingüe que no logra reconocer las prácticas dinámicas y fluidas en las que los bilingües se comprometen para producir significado y 
comunicarse en los diversos contextos de su vida diaria (Heller, 2007; García, 2009; Canagarajah, 2013). Muchos discursos a favor del bilingüismo igual terminan reproduciendo ideologías monoglósicas, pues, aunque de manera explícita rechazan el monolingüismo y proponen un bilingüismo aditivo, siguen transmitiendo ideologías en torno al desarrollo de un bilingüismo balanceado y a una igualdad de competencias en ambas lenguas. De esta manera, se asume el monolingüismo como la norma y se propone una conceptualización ideal del bilingüismo como un monolingüismo doble en dos lenguas distintas y estandarizadas, como si estas fueran objetos contables y discretos que pueden ser nombrados de manera objetiva. Desde esta perspectiva monoglósica, el bilingüismo sería la «pluralización del monolingüismo» y se comprendería solo en relación con este último (Makoni \& Pennycook, 2006). La consecuencia es que muchos bilingües con diferentes manejos de las lenguas involucradas se ven forzados a asimilarse a una norma monolingüe idealizada.

Desde estas constataciones, los investigadores en lingüística aplicada han empezado a teorizar nuevas conceptualizaciones sobre la noción de lengua. Como consecuencia, han emergido nuevos términos que intentan desafiar el discurso del déficit que enmarca la descripción de comunidades bilingües desde las ideologías monoglósicas de un monolingüismo doble. Algunos términos incluyen translenguando (García, 2009), bilingüismo flexible (Blackledge \& Creese, 2010), polylanguaging (Jørgensen, Karrebaek, Madsen \& Møller, 2011), lingualismo dinámico (Flores, 2013), prácticas transidiomáticas (Jacquemet, 2005) y translingualismo (Canagarajah, 2013). Todos estos términos se distancian de una concepción de lengua como un objeto discreto y, de esa forma, asumen los procesos de uso de las lenguas como algo fluido, complejo y dinámico. Se trata de un cambio que va desde un enfoque del bilingüismo aditivo hacia uno del bilingüismo dinámico, en que se toman en cuenta los procesos de construcción de significado de poblaciones bilingües.

En lugar de hablar de lengua como competencia acabada, se ha empezado a usar el término «repertorio comunicativo» (Rymes, 2014) para mirar lo que las personas son capaces de hacer con los recursos lingüísticos acumulados. Así entonces, en lugar de la noción amplia de competencia, debemos mirar la capacidad que tienen las personas para realizar prácticas reales en los diferentes dominios sociales en que estas pueden ocurrir. Los repertorios constituyen la lengua real que tenemos y que manifestamos en la vida social: se trata de conjuntos de recursos comunicativos funcionalmente distribuidos que están ensamblados biográficamente, y que constantemente exhiben variación y cambio. Las lenguas, entonces, se usan como parte de repertorios que los hablantes despliegan de manera flexible y estratégica. En este marco de discusión, se ha empezado a cuestionar también la distinción dicotómica entre hablante nativo (o de lengua materna) y hablante no nativo (o de segunda lengua), y han comenzado a cobrar preminencia las nociones de herencia, afiliación (Leung, Harris \& Rampton, 1997) y trayectoria lingüística (Blommaert \& Backus, 66 I 2011), que permiten mirar el aprendizaje de las lenguas como siempre ligado a 
la performance de identidades y de roles sociales, y como algo que no se reduce solo a la dimensión del expertise en la lengua.

La bibliografía más reciente sobre bilingüismo como práctica social también ha rechazado las asociaciones que se realizan entre una lengua en particular, por un lado, y una cultura, una identidad o una comunidad específica, por otro, como si se tratara de unidades delimitadas que se corresponden directamente y como si la identidad estuviera encarnada en la lengua (Heller, 2007; Canagarajah, 2013; Leeman, 2015). Sin embargo, la EIB constituye un campo discursivo dominado por ideologías esencializadoras en torno a la lengua y la identidad (Jaffe, 2007). Esto significa que, desde esta perspectiva, se asume un vínculo esencial entre la lengua quechua y las personas quechuas, como si el código se conectara icónicamente con la identidad de grupos culturales delimitados. Así, entonces, el discurso de la EIB impone identidades a los sujetos bilingües y construye como ilegítimos a muchos de ellos, sobre la base de la idea de que el hablante no usa el tipo "correcto» de lengua en función de la identidad que está reclamando (Pavlenko \& Blackledge, 2004; Shenk, 2007). No obstante, los aprendices de las lenguas también construyen sus propios patrones de uso lingüístico y de identidad, y estos patrones pueden entrar en contradicción con los patrones fijos y las identidades reificadas que se atribuyen a los aprendices desde el discurso oficial. De esta manera, se pueden producir conflictos entre identidades atribuidas por el discurso oficial y aquellas desplegadas por los propios hablantes en el marco de luchas por legitimidad y autenticación (ver Bailey, 2000; Bucholtz \& Hall, 2004; Shenk, 2007).

\section{Análisis}

\subsection{Sobre la división entre L1 y L2}

La institución que imparte el programa de formación docente en EIB asume que los estudiantes tienen al quechua como lengua materna y al castellano como segunda lengua, como solía suceder con los niños y las niñas de las escuelas rurales donde se empezó a implementar la EIB hace varias décadas. Esto resulta bastante lógico si pensamos que esta representación corresponde con la forma en que históricamente se asumió la EIB en la educación básica y que -tal como nos lo comentó una docente- la universidad debe alinearse a las políticas de EIB impartidas desde el Ministerio de Educación. No obstante, esta representación en torno a los estudiantes no coincide con la complejidad lingüística que estos muestran y desarrollan al ingresar al programa.

Si bien la mayoría de los estudiantes tienen como lengua materna al quechua, otros estudiantes son hablantes de esta lengua como lengua de herencia o son bilingües emergentes. Los bilingües emergentes (García, 2009) no pueden ser categorizados de la misma manera que los hablantes maternos y los aprendices de una segunda lengua, pues poseen características únicas. Se trata de personas que se ubican en un continuum bilingüe que deconstruye 
categorizaciones artificiales del tipo «aprendiz de una segunda lengua» versus «hablante fluido», que son difíciles de determinar. Como veremos, estos bilingües emergentes son diferentes a los hablantes maternos y de segunda lengua, debido a que han sido expuestos a la lengua y a la cultura en menor medida que los hablantes maternos, y en mayor medida que los aprendices de una segunda lengua. Muchos alumnos del programa aprendieron primero el castellano y se familiarizaron con el quechua de una forma más pasiva en diferentes momentos de sus vidas. Una alumna del programa, por ejemplo, declara:

Al momento de escribir, sigue mi pensamiento en castellano y no puedo escribir el quechua como debe ser. Yo siempre pienso en castellano primero. En quechua, estoy dificultándome. Entonces, a una compañera yo le enseño un curso que no domina, como Historia, por ejemplo, y ella me ayuda en quechua. Yo me dificulto más en el quechua.

Este tipo de alumnos no constituyen aprendices del quechua como segunda lengua. El hecho de que ellos hayan aprendido el castellano primero y que hayan hablado en esta lengua en sus hogares no significa que el quechua sea su segunda lengua, pues han estado expuestos a ella de diferentes maneras. Más bien, se les debe tratar como bilingües en todo el sentido de la palabra, y reconocer su potencialidad para acceder a un rango mayor de posibilidades expresivas y comunicativas en el futuro (García, 2005).

Además de ello, lo más importante es darnos cuenta de que muchos de los estudiantes que sí aprendieron el quechua en su primera infancia y que lo hablaron de modo predominante en su socialización temprana tampoco sienten que este constituye la lengua que mejor manejan hoy en día. Una alumna, por ejemplo, nos cuenta que dejó de hablar el quechua a los seis años «porque mis padres me prohibieron hablarlo, porque tenía problemas en el colegio». Luego, añade: «Yo me había identificado más con el castellano que con el quechua». En la misma línea, otra estudiante declara lo siguiente:

Cuando yo tenía los tres años yo hablaba full quechua y, entonces, mis tíos se molestaban que yo hablara y les decían a mis papás que no hable el quechua, entonces, no que «se ve feo», que «se escucha horrible», «no le enseñes a hablar quechua». Así poco a poco, cuando entré al jardín, nos enseñaban el castellano y empecé así a adaptarme al castellano en la primaria. Entiendo perfectamente el quechua, pero hablarlo no.

Los extractos citados nos muestran que el aprendizaje de lenguas no constituye un proceso meramente técnico con una linealidad predecible, sino que se entrelaza con cuestiones de identificación; prohibición; y, a fin de cuentas, relaciones de poder. Esto se ve muy claramente en el caso del quechua, pues la estigmatización hacia la lengua promueve que el hablante deje de usarla en diferentes períodos de su vida. En el caso presentado más arriba, por ejemplo, 
vemos que el quechua se asocia con un obstáculo para rendir bien en el colegio y no con un recurso que se podría haber aprovechado en la escolarización de la estudiante. Si bien los estudiantes del programa ingresaron a este porque supuestamente manejan la lengua originaria "como lengua materna», una vez en la institución, se enfrentan a su condición lingüística. Como hablantes de una lengua originaria oprimida, no saben escribirla, tienen vergüenza de hablarla y -cuando intentan hacerlo- sienten que se traban. Como afirmó una profesora de quechua: «El quechua no es una lengua como el castellano. Es un paralítico, tuberculoso, tísico. No es una lengua como el castellano que está ileso. Está enfermo por la discriminación y todavía no se ha recuperado».

Sin embargo, la institución no solo representa a estos estudiantes como hablantes de quechua como lengua materna, sino también como aprendices del castellano como segunda lengua, a pesar de que la mayoría de ellos ha pasado por una escolaridad enteramente en castellano y esta es la lengua que más utilizaban cuando llegaron al programa. Por ejemplo, una profesora declara: «Tienen que hacerlo en su lengua. Ahora ustedes lo están haciendo en otra lengua, esta lengua que están aprendiendo [el castellano]» (las cursivas son nuestras). Incluso, los profesores argumentan que los estudiantes no deberían estudiar inglés todavía "porque recién están afianzando el castellano como L2». En esa dinámica, se promueve una división entre «nosotros» y «ellos» a partir de las nociones de L1 y L2, pues los profesores de castellano constantemente posicionan a los estudiantes como hablantes del quechua como «lengua materna» y a ellos mismos como castellanohablantes, como si el castellano fuera una lengua ajena a los alumnos y no les perteneciera. Esto reproduce ideologías sobre la EIB fuertemente asentadas, que a veces los profesores transmiten de forma no muy consciente.

Los estudiantes no entienden por qué el programa imparte cursos de «Castellano», en los que se asume que ellos no saben esta lengua y que están en proceso de aprenderla. Constantemente, comparan estos cursos de «Castellano» con aquellos de «Lengua» que se dictan en otras carreras de la misma universidad: «¿Cuál es la diferencia entre castellano o lengua? ¿Por qué para nosotros castellano y para los demás chicos que tienen las mismas capacidades que nosotros, otra cosa?» (estudiante). Otra estudiante también señala al respecto:

Nos tomaron como si nosotros supiéramos el quechua. Sentía como que nos han arrimado a un rincón de que somos indígenas y hay que enseñarles el castellano. Si yo sé el castellano, ¿cómo me van a enseñar? Nos han hecho sentir que no sabemos hablar castellano cuando en realidad no es así.

Asimismo, la estudiante que nos contó que dejó de hablar el quechua a los seis años y que se había identificado más con el castellano que con la lengua originaria declaró que «cuando llegué aquí, me chocó darme cuenta que querían enseñarme el castellano» y que eso venía de la mano con una representación de su castellano desde un discurso de la carencia. 
Esta representación de los estudiantes como personas que están en proceso de aprender castellano viene acompañada de una ideología en la que el bilingüismo obstaculiza su desempeño en los cursos del programa y, específicamente, en la redacción en castellano. Por un lado, se asume que el no saber castellano influye en la manera en que los alumnos se desarrollan académicamente en los cursos. Una alumna lo señala claramente:

Por mi experiencia propia he sentido en algunos cursos lo inferior que te hacía sentir, porque los docentes mencionan en las clases lo siguiente: «Entiendo que no dominan el castellano; por eso, no entienden». Como si fuera que el hablar el castellano te solucionara todas las dificultades que tienes. Hay otros factores que intervienen en ello, como, por ejemplo, la educación.

En el extracto presentado, la alumna trae la voz de los docentes para revelar el nexo ideológico que se ha construido entre no dominar el castellano y no rendir bien en la universidad. Este vínculo termina por posicionar a los estudiantes (y, tal vez, a la educación básica) como los culpables de su desempeño en la universidad y por borrar la responsabilidad que tiene la educación superior en su socialización en las convenciones del lenguaje académico. No es difícil constatar que la mayoría de los alumnos maneja una variedad de castellano con la que se desenvuelve de manera fluida y solvente en espacios más informales. Sin embargo, tal y como ocurre con muchos otros alumnos castellanohablantes que acceden a la educación superior, y que no pertenecen a este programa de becas ni a la formación docente en EIB, necesitan aprender formas convencionalizadas más académicas de usar el lenguaje, tanto en el plano oral como en el escrito, con el objetivo de que se aproximen a un registro más descontextualizado y explícito en géneros discursivos propios de la educación superior. La estudiante antes citada lo plantea con mucha lucidez, pues está claro que «el hablar el castellano» (en abstracto y de forma general) no soluciona todas las dificultades que implica hablar y escribir académicamente en la universidad.

Por otro lado, esta ideología en la que supuestamente el bilingüismo obstaculiza el desempeño de los estudiantes en el programa también asume que el conocimiento del quechua termina siendo un problema y no un recurso para el desarrollo de los estudiantes en la educación superior. Uno de ellos lo revela de forma contundente:

«Ah, ustedes hablan el quechua»; con eso [los profesores], quieren decir que por eso no entendemos bien la lectura. «Ustedes hablan el quechua y por eso no pueden leer esto» y nos traían lecturas más simples. A veces, trataban de pasar la lectura a nuestra lengua. 
En esta cita, podemos observar claramente que el hablar el quechua y el no entender las lecturas están conectados en la representación que el estudiante atribuye al profesor. Nuevamente, esto borra otras variables que están en juego en el desempeño de los estudiantes en la universidad y que no son tan distintas de aquellas que también influyen en el de otros alumnos que ni son bilingües ni estudian en condición de becarios, aquellos que no llevan "Castellano» sino «Lengua». Más aún, esto termina desempoderando a los alumnos de EIB, quienes suelen sentirse fuera (o «arrimados a un rincón») de una comunidad académica que más bien debería incluir a todos. Las ideologías lingüísticas son siempre variables, y muestran contradicciones y dilemas de forma simultánea (Kroskrity, 2006). Por esta razón, a pesar de que la institución construye un discurso oficial a favor de la diversidad y que, de hecho, promueve el quechua como un recurso en muchos contextos, otro discurso -el del manejo del castellano de forma deficitaria y el de la lengua originaria como un problemase termina colando al nivel de las prácticas y los estudiantes lo perciben rápidamente.

Es importante puntualizar que estas representaciones en torno a los repertorios bilingües de los estudiantes no emergen de la propia universidad, sino que están influidas por ideologías históricamente asentadas en el Estado y la sociedad. Como señalan Degregori y Huber, las propuestas oficiales sobre la EIB «revelan las contradicciones de un Estado que antes rechazó la diversidad cultural de su sociedad para luego aceptarla en el plano meramente declarativo a partir de la Constitución de 1993, pero sin dar señales significativas de querer llevar a la práctica ese enunciado constitucional» (2007, p. 481). A pesar de que en los últimos años se han generado avances importantes en las políticas de EIB, todos sabemos que son precisamente los cambios ideológicos los que toman más tiempo.

\subsection{Sobre las trayectorias de aprendizaje}

En esta sección, presentaremos tres casos de estudiantes que se encuentran en el programa. Los tres estudiantes tienen aproximadamente veinte años y son los primeros en su familia que estudian educación superior. En lugar de quedar entrampados por concepciones de lengua, de competencia y de comunidad que funcionan a priori, nos enfocaremos en las trayectorias que han seguido a lo largo de sus vidas: las oportunidades, las limitaciones y las desigualdades que enfrentan, los ámbitos de aprendizaje a los que tuvieron acceso (y a los que no tuvieron acceso), su movilidad a través del espacio físico y social, y su potencial para tener voz en ámbitos sociales particulares.

Cuando uno conversa con estos estudiantes, nota que los patrones de aprendizaje de las lenguas son muy diversos e involucran un amplio rango de tácticas, tecnologías y mecanismos a través de los cuales una persona se apropia de recursos lingüísticos como parte de su repertorio. Dentro de este marco, el término adquisición no resulta muy productivo, pues sugiere un producto 
acabado (en el sentido de recursos que se han adquirido alguna vez y para siempre), mientras que el de aprendizaje contempla la posibilidad de que uno puede desaprender y olvidar lo que alguna vez aprendió. El conocimiento real de una lengua, como cualquier aspecto del desarrollo humano, depende de la biografía de la persona, la cual es siempre dinámica. Además, cada una de estas trayectorias es única y contribuye con el repertorio de una persona en más que solamente material lingüístico: permite potencialmente desarrollar ciertos roles sociales, habitar ciertas identidades y ser visto por otros de formas particulares. Estos repertorios nos permiten analizar los itinerarios sociales y culturales que siguen las personas, cómo maniobraron y navegaron en ellos, y cómo se situaron en los variados contextos sociales que habitaron en sus vidas.

El primer caso muestra que el contraste rígido entre la primera y segunda lengua no resulta muy claro, pues, como en muchas otras ocasiones, lo que en algún momento fue la primera lengua de una persona puede perder funcionalidad y dar paso a una lengua adicional que se termina convirtiendo en su lengua dominante (Duff, 2011). Esta pérdida de funcionalidad, como veremos, se relaciona con el hecho de que Emuri, el estudiante cuyo caso analizaremos primero, se va moviendo a un ámbito cada vez más urbano conforme pasan los años, y esto lo va «incapacitando» en sus habilidades con la lengua originaria y en su posibilidad de tener voz en estos nuevos espacios ${ }^{2}$.

Emuri nació en una comunidad quechuahablante apurimeña, en un distrito «donde toda la gente habla quechua y todos se comunican en quechua»: «Mi lengua materna ha sido todo quechua hasta que llegué a la escuela». En la escuela primaria, sufrió mucho por no hablar el castellano: «Aprender otra lengua, adaptarte a otra lengua que no es el tuyo, que no lo has dominado desde pequeño es más que todo un choque, yo diría un choque así muy trágico». Aunque en sexto grado ya «dominábamos más o menos», «no tomaba el castellano como mi lengua, sino como segunda lengua». Durante la secundaria, sus papás lo llevaron a la selva del Cusco, en donde los demás estudiantes de su colegio hablaban más castellano y lo discriminaban por hablar el quechua. Como consecuencia, dejó de hablar la lengua originaria: «ya el quechua para mí era como segunda lengua, para nada, cuando llegaba a mi casa también a mi mamá le hablaba en castellano, porque no me gustaba lo que me trataban y quería aprender más». Al terminar la secundaria, se mudó a la ciudad del Cusco, donde el quechua «ya no era necesario». La pérdida de la lengua originaria era inminente: «En ese momento, para mí, era normal. Y yo tenía otro pensamiento ese rato. Cuando todos decían que castellano es la mejor lengua, entonces, ya te mentalizas y dices entonces es hora de dejar mi lengua». Hace un año, vino a Lima para estudiar la carrera de Educación Intercultural Bilingüe con una beca del gobierno y ahora siente que necesita recuperar su lengua. A diferencia de su experiencia en la escuela, cuando no podía hablar en castellano y se le «salía

2. Hemos optado por no usar seudónimos, sino por colocar los verdaderos nombres de los participantes, pues ellos pidieron que así fuera. 
el mote», ahora intenta hablar en quechua y «se me mete castellano»: "Ya no puedo hablar [en quechua] lo que antes hablaba. Por eso, ya [el castellano] en una lengua principal se ha vuelto».

Sentía un miedo que mi boca mismo se cerraba cuando hablaba quechua; o sea, tú sientes cuando estás al frente de todos, quieres hablar quechua y no te sale porque o sea la práctica misma te ha enseñado que quechua es malo. Castellano fluye, pero quechua no puedes; hasta tu misma boca se amarra y no puedes formar palabras, no se puede. Y eso es lo que pasó. Anteriormente, nos han dado esa idea de que quechua no vale nada. Hasta mi papá mismo, me decía «tienes que aprender castellano" y él mismo me hablaba en castellano, pero yo como era niño y joven hacía caso, ¿no? Y todo lo hablaba en castellano hasta que ahora lo necesito [quechua]. Por eso, ahora mi papá, ahora que le llamo, ya me habla en quechua.

Algunos autores (cfr. Blommaert, Collins \& Slembrouck, 2005) han señalado que las personas con habilidades multilingües desarrolladas pueden sentirse incapacitadas comunicativamente cuando se encuentran «fuera de lugar». Un cambio en el ámbito espacial (como, por ejemplo, un cambio del ámbito privado al ámbito público o de una zona más rural a una más urbana en el caso del quechua) claramente afecta la capacidad de los usuarios para desplegar recursos lingüísticos y habilidades, e impone requerimientos en ellos. Por lo tanto, no estamos hablando de un problema del hablante, sino de un problema para el hablante producido por los requerimientos del ámbito, en el sentido de que la función y el valor de los recursos en ese ámbito en particular tienen otros significados. Es el espacio social, entonces, el que condiciona, en gran medida, la organización de patrones de bilingüismo y multilingüismo. En muchas historias recogidas, la ciudad siempre aparece como un lugar de "contención» en relación con el uso de la lengua, que contrasta con la libertad que existe en la zona rural para poder hablarla, y que se asocia con un espacio de discriminación y de negación de su condición de persona y -por tanto- de ciudadano. Aunque ahora que está en la especialidad de EIB Emuri intenta hablar más quechua que antes, Lima representa un escenario que lo sigue incapacitando en sus habilidades con el quechua: «En Lima ya, nadies habla, y acá más que todo tienes un miedo a que cuando hablas quechua te van a discriminar total. Ese miedo es lo que no nos deja hablar».

Aunque el siguiente caso también se relaciona con cómo el poder afecta la capacidad de los hablantes, nos muestra además cómo los repertorios son conjuntos de recursos que están organizados biográficamente y que siguen el ritmo de las vidas de las personas. Esto significa que los repertorios no se desarrollan a lo largo de un camino lineal que va aumentando cada vez, sino que muchas veces se desarrollan de manera explosiva en algunas fases de la vida y gradualmente en otras. En ese sentido, son el resultado de experiencias de 
aprendizaje policéntricas. Un fenómeno que precisamente se aprecia en relación con el quechua es que su aprendizaje y uso no es continuo: se manifiesta, pero también desaparece en momentos específicos de la vida de las personas.

El siguiente es el caso de Milady. Ella nació en la ciudad de Ayacucho. Su madre era madre soltera y había migrado de la zona rural a la ciudad, en donde "se puso a hablar más castellano»: "Crecí en una familia que hablaba como lengua materna el quechua, pero hablaba en castellano por necesidad». Aunque la mayor parte de su vida vivió en esta ciudad al lado de su madre (y se socializó en castellano), en diversos momentos de su vida, pasó largos períodos en la zona rural con diversos familiares y esto le posibilitó el aprendizaje del quechua. De esta manera, su desplazamiento fue al revés del de Emuri, pues migró varias veces hacia zonas más rurales en lugar de a zonas más urbanas.

Cuando tuvo tres años, su mamá la llevó a la zona rural a vivir dos años con sus abuelos: «Creo que fui aprendiendo qué es lo que quiere decir en quechua, pero a hablar no». A los cinco años volvió con su mamá a la ciudad para estudiar educación inicial, donde todo era en castellano en el ámbito escolar. El único vínculo con el quechua era la mamá de su padrastro con quien se quedaba cuando su mamá se iba a trabajar: «Yo la llamaba en quechua, pero no le hacía una conversación larga; le decía ciertas palabras y hay algunas cosas que aprendí de ella, cómo llamar a las cosas, por ejemplo». Es más, aunque su mamá le hablaba todo en castellano "porque pensaba que yo no entendía el quechua», «a veces cuando venía una visita a la casa, ellos hablaban en quechua y yo a veces por curiosidad me acercaba, les oía e iba alimentando mi vocabulario poquito a poquito». Recuerda que estas conversaciones entre adultos eran una oportunidad de aprendizaje, pues a ella le gustaba escuchar el quechua y siempre quería estar ahí.

Luego de un año de estar en la ciudad, a los siete años, su mamá la llevó a vivir con su bisabuelo a Lucanas y ahí estudió en la escuela rural, donde todos los niños hablaban quechua: "Ahí sí como que aprendí más. Admiraba a mis primas. Yo nunca había visto a un niño a hablar quechua así seguido, corrido, hablar quechua con una persona mayor y ellas sí lo hacían». Luego de ese año, regresó nuevamente a la ciudad, donde se quedó varios años, «y ahí como que olvidé el quechua».

Cuando tuvo que matricularse en cuarto de secundaria, le pidieron DNI y ella no pudo conseguirlo a tiempo, porque tuvo problemas con su partida de nacimiento. Como consecuencia, tuvo que irse a vivir a Cangallo con la familia de su papá para finalizar el colegio. Aunque el colegio «era todo en castellano», la zona era más quechuahablante que la ciudad de Ayacucho: «Mis hermanitos también castellano hablaban, pero así para insultarse, para hablar entre nosotros, para hablar con sus abuelitos ellos hablaban en quechua». Sin embargo, esta movilidad de la zona urbana a la zona rural a los quince años también la limitó en el despliegue de sus recursos y habilidades en lengua originaria, pues los otros la percibían como «fuera de lugar» y no le hablaban en quechua: «Yo también saludaba en quechua, algunas palabras, creo que algunos me miraban 
“esta de dónde vino?” y, a veces, murmuraban en quechua, pero yo les entendía; ellos pensaban que yo no les entendía». Incluso, cuenta que en el colegio los compañeros hablaban en quechua entre ellos, pero a ella no le hablaban en quechua: «Me sentía como que ellos pensaban que yo no podía hablar el quechua, pero yo no les decía nada y les contestaba en castellano». El valor indexical del quechua (y el hecho de que se asocia con alguien que no sabe hablar castellano y que es de zona rural) se presentó como una limitación para que Milady pudiera desplegar su voz en la lengua originaria.

Luego de ese año, volvió a Huamanga y «ahí ya perdí de hablar el quechua»: «Dejé de hablar el quechua, de escucharlo también». Cuando tuvo oportunidad de presentarse para la beca, Milady sentía que no podía hablar quechua, aunque sí se «defendía» en leer y escribir, pues su mamá había sido promotora de alfabetización en ambas lenguas y traía libros de harawi, cuentos y adivinanzas en la lengua originaria: «Yo me ponía a leer así, a palabrear así». Esta oportunidad que supo aprovechar le ayudó a pasar el examen para la beca: "Había una canción que hemos bailado en el colegio; a veces, las canciones son en quechua y tenías que aprendértela para cantar en pleno baile, y, entonces, escribí esa canción y creo que eso me salvó».

A pesar de que se le podría considerar una bilingüe emergente, que ha vivido más en la zona urbana, ella se siente muy identificada con la lengua originaria y con el modo de vida más rural:

Nací en la ciudad, pero provengo de una familia quechuahablante, pero tampoco tengo como lengua materna el quechua, sino que yo primero aprendí el castellano, pero a veces yo me identifico más con lo rural, porque mi familia es de ahí, tanto mi mamá como mi papá es de ahí. Me identifico más con la gente de zona rural.

Aunque le pesa no haber aprendido más quechua, ahora siente que la lengua está aflorando poco a poco en su vida. Incluso, tiene un cuaderno en el que traduce baladas al quechua, trata de buscar adjetivos diversos para determinados sustantivos y anota palabras nuevas. Además, ha empezado a hablar más con su abuelita y también por Facebook con sus primos: «Todo lo que quiero decir lo tengo aquí, pero al momento de hablar se me va, se me escapa. No sé; no lo puedo decir».

El tercer caso muestra nuevamente el planteamiento de Leung et al. (1997) con respecto a la poca utilidad de la distinción entre hablante nativo y no nativo, y a la importancia de tomar en cuenta la identificación o apego que la persona siente por la lengua, así pertenezca o no nominalmente al grupo social que se suele asociar con ella. Percy nació en una comunidad campesina de migrantes de la zona andina en el Vrae en el distrito de Kimbiri (Villa Quintiarina), provincia de la Convención (región Cusco). Su familia tenía contacto con personas matsiguengas que vivían a una hora y que, a veces, iban a trabajar en actividades colectivas. Según declaró, su lengua materna es quechua por 
influencia de sus padres y el castellano recién lo aprendió en la escuela. Aunque recuerda que en la escuela les hacían cantar el himno nacional en quechua y que su profesora sabía hablar quechua porque era cusqueña, «en el salón de clase solo nos habló en español»:

La lengua española, nos decía la profesora, que es para tu vida y para cualquiera te sirve para que te puedas defender en la secundaria, en la universidad. Además, cuando vas a ir a estudiar superior, siempre vas a hablar esta lengua y en cualquier parte. Pero ahora me doy cuenta que no, pero eso es lo que decía y, además, nos decía ya no van a ser igual que sus padres con esa lengua no más que se van a quedar. Y ya poco a poco tenía que aprender, aunque difícil pero sí.

Cuando estaba en cuarto grado, migró de su comunidad campesina al poblado más cercano y, al igual que en los casos anteriores, este movimiento de ámbito afectó sus habilidades multilingües: «Cuando hablabas quechua te trataban un poco menos; a veces, no quería jugar contigo». Más aún, en secundaria, los profesores eran de Ica o de Lima, y no les permitían hablar quechua. Percy cuenta cómo el ámbito más urbano fue haciendo desaparecer el quechua en la vida de su familia:

En San Antonio, tenía la ideología que el castellano lo era todo, para ir a comprar, para ir a estudiar, en todo lugar, para jugar con tus amigos, hasta en la casa ya también comenzamos a hablar. Hasta mi mamá, no sabía y comenzó a hablar, porque vendía productos; para que venda, tenía que hablar en español. En la actualidad, ya no hablamos quechua en la casa también. Por eso, me he decidido a hablarles en quechua a todos (a partir de su ingreso al programa de formación docente en EIB). En mi casa, prácticamente es puro español. Hasta mi padrastro, que no sabía nadita de castellano, ahora ya sabe.

Ahora bien, cuando él tenía diez años, su tía (la hermana de su mamá) se casó con un matsiguenga. Hasta entonces, Percy solo conocía algunas palabras de esa lengua, porque los matsiguengas solían venir a su comunidad a trabajar la chacra:

Además, venían matsiguengas a mi casa a preparar masato, y preparaban masato y hablaban matsiguenga. Y yo no sabía qué estaban hablando; no sabía que era matsiguenga, nada. Simplemente, son nativos nada más. Pensaba que estaban hablando en otra lengua extranjera algo así.

Poco a poco, comenzó a ir a visitar a sus primos algunos fines de semana: «Ellos hablaban matsiguenga, pero también un poco de quechua cuando hablaban conmigo». Sin embargo, poco a poco, pidió que le enseñaran a hablar porque le interesaba aprender. Cuando tenía trece años, se quedó una tempo- 
rada de cuatro meses con ellos, porque hubo una huelga del magisterio y no pudo ir al colegio. A partir de esa experiencia, su tía ya no le hablaba en quechua, sino en matsiguenga: «diariamente, me hablaba».

Aunque Percy es fluido en quechua y no tanto en matsiguenga, en términos de afiliación, se siente muy cercano a la cultura matsiguenga: «En el programa, me siento selvático como matsiguenga, aunque no me crean, pero así me siento. Soy distinto y, cuando comienzan a rajarse de la cultura matsiguenga o ashaninka, digo que no es así. Defiendo esa posición». A veces, se pone su cushma y «me identifico más con ellos». Aunque se identifica con el quechua, le interesa mucho la cultura matsiguenga: «Me lo sé un montón de ellos: qué comían, qué hacían, qué pensaban, qué cosmovisión tenían. No sé; me interesa más y me gusta esa vida, cómo curan y todo». No obstante, cuando está con su familia, se siente quechua.

Además, también usa el matsiguenga para escribir poesías y otro tipo de textos: «Palabras lo agrego; es chévere. Por ejemplo, hay palabras que no puedes traducirlo, como las flores de la selva o los sonidos; no lo puedes traducir al quechua ni al español». Desde que estaba en secundaria, escribe diversos tipos de textos combinando las tres lenguas, aunque la lengua no marcada o la lengua base es ahora el castellano:

La combinación se ve bonito y, cuando lo hablas, estás hablando puro español y de un momento cambias en quechua y es algo que llama la atención. Lo cambias y, a veces, cuando no están atendiendo, te prestan atención y más cuando lo cambias al matsiguenga; se preguntan, ¿no? Y luego vienen a preguntarte. El sonido también cambia; no es igual. Es interesante hacer esto.

Además, es importante puntualizar que, al igual que en el caso anterior, la escritura en lengua quechua ya era parte del repertorio de Percy antes de que ingresara al programa. Cuando era pequeño, logró desarrollar la escritura quechua en un ámbito de aprendizaje particular: la religión evangélica. Según Percy,

Mi abuelita me hacía leer en quechua para que pueda entender, porque no lee ella. Siempre me llamaba, porque me gustaba leer y me gustaba hablar de Dios; a mis hermanos no les gustaba. Yo le leía. Así, aprendí a leer y también a escribir. No había ni curso ni taller, solo con la Biblia.

Percy declara que hay muchas palabras del quechua que se ha olvidado. Ante esto, aplica una serie de tácticas que lo están ayudando a recordar: «Trato de buscar y buscar, y, a veces, encuentro. Me recuerdo y trato con la memoria». Además, habla en quechua (y en matsiguenga) por celular con su mamá y acude a su abuelita cuando necesita que lo ayude en algún trabajo para la universidad. 
Como vemos, no podemos clasificar a estos estudiantes como ciertos tipos de bilingües con dicotomías simplificadoras. Cada uno habla las dos (o tres lenguas), pero no son monolingües «dobles» o «triples», ni tampoco estas están internamente relacionadas con una «cultura» en particular. Echan mano de recursos de cada lengua como parte de su repertorio individual y seleccionan elementos de cada una, según los necesitan, para lograr un propósito particular. Los repertorios de estas personas son, además, trazos complejos de poder, en el sentido de que sus posibilidades y sus limitaciones están dictaminadas por los diferentes ámbitos, las normas y las expectativas sociales que los gobiernan. Después de todo, la voz siempre está sujeta a un juicio normativo, pues alguien tiene voz cuando otro lo ratifica.

\section{Reflexiones finales}

A lo largo de este artículo, hemos intentado mostrar el desfase entre la complejidad de bilingüismos y multilingüismos, y algunas conceptualizaciones reduccionistas del discurso de la EIB, que todavía se resisten a desaparecer, a pesar de las innovaciones que se vienen desarrollando en los últimos años. Necesitamos introducir conceptualizaciones más sofisticadas sobre la EIB, y el rol de las prácticas lingüísticas y culturales en la educación. Aunque el uso de las lenguas y las identidades sociales se han ido modificando en las últimas décadas, y están desafiando algunas categorizaciones de la EIB, este discurso sigue reproduciendo una clasificación de las identidades lingüísticas de los estudiantes como lo hacía hace algunas décadas. Sabemos que los cambios que se están formulando desde las políticas educativas (en relación con los diversos y nuevos escenarios sociolingüísticos de la EIB, por ejemplo) inevitablemente arrastran paradigmas anteriores que están históricamente asentados y que son difíciles de transformar en poco tiempo. Necesitamos, entonces, desarrollar espacios ideológicos que promuevan ideologías lingüísticas heteroglósicas, pero también espacios de implementación que nos orienten sobre qué deberíamos hacer en las aulas.

La dicotomía entre L1 y L2 no permite apreciar la diversidad de casos de estudiantes en los procesos de formación en EIB. Podemos mencionar el caso de alumnos quechuas -o boras en la Amazonía- que aprendieron la lengua indígena como lengua materna, pero que luego dejaron de usarla en ciertos períodos de sus vidas; el caso de alumnos quechuas que se socializaron con el castellano durante su niñez, pero que pueden ser clasificados como bilingues emergentes; el caso de estudiantes de la lengua cocama que aprendieron solo el castellano durante su niñez y que escucharon la lengua originaria en menor medida que los alumnos quechuas que acabamos de mencionar; o el caso de algunos estudiantes matsés que quizás sí deberían aprender el castellano con metodología de L2, pues tienen un castellano muy incipiente que no les permite entender los cursos impartidos en esta lengua. De hecho, aunque el programa estudiado cuenta con algunos alumnos con estas características, estos constituyen un porcentaje muy reducido. Ahora bien, a pesar de esta diversi- 
dad de casos, y en alineación con las políticas de EIB que han dominado en la educación básica, la institución de educación superior construye una representación de los becarios como hablantes de quechua como L1 y castellano como L2 desde un discurso que -por momentos- se acerca al déficit, y que, además, tiene el riesgo de invisibilizar la problemática del aprendizaje del lenguaje en su variedad académica. De hecho, la problemática del dominio de una variedad académica del español no constituye un reto particular de esta población, sino que se evidencia también en distintos otros integrantes de la comunidad universitaria, con biografías incluso altamente distintas.

Más aún, la dicotomía entre L1 y L2 tampoco nos permite ver que muchos estudiantes llegan al programa con un quechua «trabado» y que la institución debería contemplar políticas en función de esta problemática. Por ejemplo, así como los alumnos deben llevar un año de «nivelación» en castellano antes de ingresar a los cursos regulares de la carrera (lo que, por cierto, se puede cuestionar), deberían también «nivelarse» -o, más bien, empoderarse- en la lengua originaria apenas llegan al programa para que esta vuelva a emerger con más seguridad y confianza. No obstante, como se asume que los estudiantes tienen al quechua como lengua materna, durante este primer año remedial, llevan todo en castellano y la institución no se ocupa del quechua, como si se tratara de un asunto ya resuelto.

Esta representación de los becarios como hablantes de quechua como L1 y castellano como L2, que pone en cuestionamiento su competencia lingüística en castellano y a veces asume el quechua como un obstáculo para el aprendizaje en la educación superior, se podría enmarcar en las ideologías raciolingüísticas que se han venido discutiendo para otros contextos (Flores \& Rosa, 2015; Alim et al., 2016). Este marco teórico cambia el foco de atención de los hablantes y sus prácticas lingüísticas hacia los oyentes, y la percepción que estos tienen de ellas. A su vez, sostiene que los oyentes nunca perciben las prácticas lingüísticas de los hablantes de forma objetiva, sino siempre bajo el tamiz de su posición (racializante) en la estructura social. De esta manera, las ideologías raciolingüísticas fusionan ciertos cuerpos racializados con deficiencia lingüística, más allá de la existencia o no de prácticas lingüísticas objetivas. Lo que hemos visto en el caso estudiado es que los repertorios bilingües de los estudiantes son percibidos por la institución desde una ideología de «carencia de lenguaje» -o languagelessness, en inglés- (Rosa, 2016), que asume la capacidad lingüística limitada de un grupo social. No obstante, esta percepción del castellano de los estudiantes desde un discurso del déficit y del quechua como un problema en la educación superior puede no necesariamente coincidir con las prácticas lingüísticas objetivas y las habilidades con el lenguaje que los estudiantes despliegan. Después de todo, nunca accedemos a la realidad de forma neutral y directa, sino siempre a partir de la mediación de ideologías, valoraciones y todo tipo de regulaciones (Hall, 2010).

Otro punto que hemos querido enfatizar en este artículo es el paso de la noción de lengua a la noción de repertorio. Como hemos podido apreciar en 
los casos presentados, no podemos clasificar a estas personas en hablantes o en no hablantes de la lengua originaria, pues, por lo general, cuentan con diversos recursos comunicativos que se distribuyen y funcionan de manera diferenciada en el marco del repertorio. Después de todo, la lengua que sabemos nunca está acabada e involucra un aprendizaje de ciertos registros, estilos, géneros y variedades lingüísticas, mientras que se pierden o alteran otros que existían antes. Además, hemos visto que es importante ir más allá de la dimensión del expertise en la lengua para tomar en cuenta dimensiones identitarias que siempre se conectan con el expertise. Los profesores, entonces, no solo deberían preocuparse por saber si el estudiante habla la lengua originaria como lengua materna o como segunda lengua, sino por saber con qué tipos de repertorios comunicativos cuentan y si la relación del estudiante con cada lengua se basa en el expertise, la herencia o la afiliación, o en una combinación de estos aspectos. Si las personas asumen que saber una lengua implica dominar un código discreto, acabado, estático y definido, dirán que no saben la lengua o que no son hablantes de la lengua, y se sentirán deslegitimados cuando -en realidadpueden conocer elementos de la lengua en el marco de un repertorio comunicativo que despliegan en diferentes circunstancias.

El caso de Milady es interesante al respecto. Cuando ella ingresó a la universidad, sintió que su quechua era muy débil y que su lugar en el programa podía verse amenazado, a pesar de que sentía una fuerte afiliación e identificación con la lengua. Su preocupación la llevó a desarrollar una serie de estrategias para potenciar su repertorio comunicativo en la lengua originaria. Luego de dos años y medio en el programa de formación, ya entiende las clases en la lengua originaria. Es más, hace unos meses, se presentó a un concurso de poesía en quechua convocado por la Universidad Nacional Mayor de San Marcos y obtuvo el primer puesto.

La sociolingüística tradicional y el discurso de la EIB han enfatizado la conexión de las lenguas minorizadas con lugares específicos (Blommaert, 2010). Sin embargo, la noción de trayectoria de aprendizaje de los recursos bilingües resulta fundamental para darnos cuenta de que la conexión mencionada ya no se sostiene y que hay que movernos del enfoque de comunidades al de los sujetos que se mueven. En lugar de asumir la estabilidad de las comunidades, deberíamos fijarnos en la fluidez de las redes, las comunidades de práctica y las comunidades de conocimiento. Todas estas son dinámicas y forman parte de la vida de los sujetos en períodos específicos de sus vidas. Por lo tanto, los repertorios no son propiedades estáticas y sincrónicas de una comunidad de habla, sino que se desarrollan a partir de la participación dinámica, cambiante y negociable de los sujetos en diferentes comunidades. Así lo han mostrado las historias de Emuri, Percy y Milady. Debemos pasar, entonces, de un bilingüismo aditivo a un bilingüismo dinámico, en el que empecemos a problematizar -de modo estratégico- aquellos esencialismos que nos vienen acompañando por varias décadas y que no nos ayudan a comprender las transformaciones sociolingüísticas del Perú de hoy. La división entre L1 y L2 es uno entre tantos. 


\section{Notas biográficas}

Virginia Zavala

Es Ph.D en Sociolingüística por Georgetown University en Estados Unidos y profesora principal de la Pontificia Universidad Católica del Perú. Sus investigaciones abordan la problemática de la lengua y la educación desde una perspectiva etnográfica y de análisis del discurso.

ROBERTO BRAÑEZ

Es magíster en Lingüística por la Pontificia Universidad Católica del Perú y profesor por la misma universidad y la Universidad Antonio Ruiz de Montoya. Sus intereses se concentran en el campo de la Comunicación Mediada por Computadoras, con especial énfasis en la construcción de subjetividades racializadas y generizadas en el ciberespacio peruano. 


\section{Referencias}

Alim, H. S., Rickford, J. \& Ball., A. (Eds.) (2016). Raciolinguistics: How language shapes our ideas about race. New York: Oxford University Press.

Bailey, B. (2000). Language and negotiation of racial/ethnic identity among Dominican Americans. Language in Society, 29, 555-582.

Blackledge, A. \& Creese, A. (2010). Multilingualism: A critical perspective. London: Continuum.

Blommaert, J. (2010). The sociolinguistics of globalization. Cambridge: Cambridge University Press.

Blommaert, J. \& Backus, E. (2011). Repertoires revisited: «Knowing language» in superdiversity. Working Papers in Urban Language and Literacies, 67.

Blommaert, J., Collins, J. \& Slembrouck, S. (2005). Spaces of multilingualism. Language \& Communication 25, 197-216.

Bucholtz, M. \& Hall, K. (2004). Language and identity. In A. Duranti (Ed.), A companion to linguistic anthropology (pp. 369-394), Vol. 1. Oxford: Blackwell.

Canagarajah, S. (2013). Translingual practice. Global englishes and cosmopolitan relations. New York: Routledge.

Degregori, C. I. \& Huber, L. (2007). Cultura, poder y desarrollo rural. Lima: Sepia.

Duff, P. (2011). Second language socialization. In A. Duranti, E. Ochs \& B. Shieffelin (Eds.), Handbook of language socialization (pp. 564-586). Oxford: Blackwell.

Flores, N. (2013). Silencing the subaltern:Nation-state/colonial governmentality and bilingual education in the US. Critical Inquiry in Language Studies, 10(4), 263-287.

Flores, N. \& Rosa, J. (2015). Undoing appropriateness: Raciolinguistic ideologies and language diversity in education. Harvard Educational Review, 85(2), 149-171.

García, O. (2005). Positioning heritage languages in the United States. Modern Language Journal, 89(4), 601-605.

(2009). Bilingual education in the 21st century. A global perspective. New York: Wiley-Blackwell.

García, O., Flores, N. \& Spotti, M. (2017). Introduction. Language and society: A critical poststructuralist perspective. The Oxford Handbook of Language and Society. Oxford: Oxford University Press.

Hall, S. (2010). El trabajo de la representación. En E. Restrepo, C. Walsh \& V. Vich (Eds.), Sin garantías (pp. 445-480). Lima: Instituto de Estudios Peruanos. 
Heller, M. (2007). Bilingualism as ideology and practice. En M. Heller (Ed.), Bilingualism: A social approach (pp. 1-22). New York: Palgrave.

(2011). Paths to post-nationalism: A critical ethnography of language and identity. Oxford: Oxford University Press.

Irvine, J. T. \& Gal, S. (2000). Language ideology and linguistic differentiation. In P. Kroskrity (Ed.), Regimes of language. Ideologies, polities and identities (pp. 35-84). New Mexico: School of American Research Press.

Jacquemet, M. (2005). Transidiomatic practices: Language and power in the age of globalization. Language \& Communication, 25(2005), 257-277.

Jaffe, A. (2007). Discourses of endangerment: Contexts and consequences of essentializing discourses. En A. Duchene \& M. Heller (Eds.), Discourses of endangerment. London: Continuum.

(2015). Defining the new speaker: Theoretical perspectives and learner trajectories. International Journal of the Sociology of Language, 231, 21-44.

Johnson, D. C. (2013). Language policy. Basingstoke: Palgrave Macmillan.

Jørgensen, J., Karrebaek, M. S., Madsen, L.M. \& Møller, J. S. (2011). Polylanguaging in Superdiversity. Diversities, 13(2).

Kroskrity, P. (2006). Language ideologies. In A. Duranti (Ed.). A companion to linguistic anthropology. Malden, MA: Blackwell.

Leeman, J. (2015). Heritage language education and identity in the United States. Annual Review of Applied Linguistics, 35, 100-119.

Leung, C., Harris, R. \& Rampton, B. (1997). The idealized native speaker, reified ethnicities and classroom realities. Tesol Quarterly, 31(3), 543-560.

Ley 28044, Ley General de Educación (2003)

Ley 29735, Ley que regula el uso, preservación, desarrollo, recuperación, fomento y difusión de las lenguas originarias del Perú (2016).

Makoni, S. \& Pennycook, A. (Eds.). (2006). Disinventing and reconstituting languages. Clevedon: Multilingual Matters.

Ministerio de Cultura (2017). Política Nacional de Lenguas Originarias, Tradición Oral e Interculturalidad del año 2017. Lima.

Ministerio de Educación (2016). Política Sectorial de la Educación Intercultural y la Educación Intercultural Bilingüe. Lima.

Pavlenko, A. \& Blackledge, A. (2004). Negotiation of identities in multilingual contexts. Clevedon: Multilingual Matters.

Pennycook, A. (2001). Critical applied linguistics: A critical introduction. New Jersey: Lawrence Erlbaum.

(2010). Language as local practice. London: Routledge.

Rymes, B. (2014). Communicating beyond language. Everyday encounters with diversity. London: Routledge. 
Rosa, J. (2016). Standardization, racialization, languagelessness: Raciolinguistic ideologies across communicative contexts. Journal of Linguistic Anthropology, 26(2), 162-183.

Shenk, P. S. (2007). «I'm Mexican, remember?» Constructing ethnic identities via authenticating discourse. Journal of Sociolinguistics, 11, 194-220.

Van Deusen-Scholl, N. (2003). «Toward a definition of heritage language: sociopolitical and pedagogical considerations». Journal of Language, Identity, and Education, 2(3), 211-230.

Zavala, V., Mujica, L., Córdova, G. \& Ardito, W. (2014). Qichwasimirayku. Batallas por el quechua. Lima: Fondo Editorial PUCP. 